\title{
Estado DE LA FONOLOGÍA SEGMENTAL DEL MAPUdUNGUN DE ESCOLARES LAFKENCHES DE LA COMUNA DE TIRÚA: RASGOS PROMINENTES*
}

\author{
Marisol Henríquez Barahona**
}

\section{Resumen}

En este artículo se presenta una descripción del sistema fonológico del mapudungun de escolares lafkenches ${ }^{1}$ de la Provincia de Arauco, Región del Bío-Bío. Específicamente, comparamos este sistema fonológico con el que se presenta en las descripciones fonemáticas existentes del mapudungun en general y del mapuche de Tirúa en particular. La muestra está conformada por un grupo de 20 escolares mapuche de entre 12 y 15 años de la comuna de Tirúa. La recolección del material fonético-fonológico se realizó a través de una lista léxica de 64 items y de la elicitación de vocabulario de un cuento en mapudungun. En términos generales, destacamos la presencia de una serie de rasgos fónicos que caracterizan la fonología de los niños de ambas localidades estudiadas y que pueden ser atribuidos a la influencia del castellano.

Palabras claves: Mapudungun, fonología, rasgos prominentes, escolares de Tirúa.

\section{StATUS Of THE MAPUdUNGUN SEGMENTAL PHONOLOGY IN LAFKENCHES STUDENTS FROM TIRÚA: SALIENTFEATURES}

\begin{abstract}
This paper aims at describing the Mapudungun's phonological system of Lafkenches students from the province of Arauco, BioBio region. This phonological system is compared to the one that is present in the phonemic descriptions that exist in Mapudungun in general and in the Tirúa variant of Mapuche in particular. The sample is made up of 20 eighth graders whose age ranges between 12 and 15 . The participants attend Tirúa's rural schools. The phonetic and phonological data collection was carried out through a 64 lexical item list and vocabulary elicitation from a short story in Mapudungun. In general terms, a series of phonics features are identified among the participants. These features define the phonology of each participant, which can be attributed to the Spanish influence.
\end{abstract}

Keywords: Mapuche language, phonology, salient features, Tirúa students.

Recibido: 25-09-2015

Aceptado: 22-01-2016

** Chilena. Doctora en Lingüística de la Universidad de Concepción. Académica de la Universidad Católica de la Santísima Concepción. Concepción. Chile. mhenriquez@ucsc.cl

Agradecemos a todos los escolares de la zona de Tirúa que participaron voluntariamente en este estudio. Sin su colaboración esta investigación no habría sido posible. 


\section{Introducción}

Las últimas investigaciones relacionadas con el estado del mapudungun $^{2}$ en Chile sostienen que la vitalidad de la lengua y, por lo tanto, su viabilidad, parecen encontrarse amenazadas, debido al avance progresivo del castellano. Según los investigadores, este proceso de retracción se observa, principalmente, en la disminución del número de hablantes, en la pérdida de ámbitos de uso tradicionales y en el quiebre de la transmisión intergeneracional (Zúñiga, 2007; Durán et al., 2007; Gundermann et al., 2008, 2009; Lagos, 2012; Henríquez, 2014, etc.).

El problema del mantenimiento de la lengua originaria por parte de la población mapuche es una de las consecuencias directas del contacto histórico y asimétrico entre estas dos sociedades. El castellano, la lengua de prestigio, ha penetrado de manera significativa en la vida interna de las comunidades, provocando la restricción funcional del vernáculo. Tal situación de desplazamiento se observa principalmente en el segmento generacional de los jóvenes y niños mapuches (Salas, 1992a; Zuñiga, 2007; Gundermann et al., 2008, 2009; Henríquez, 2014).

Según datos proporcionados por Gundermann y otros, el grupo etario de entre 10 y 19 años es el que presenta menor desempeño en la lengua mapuche, puesto que sólo un 14,3\% comprueba competencia, concentrándose en los niveles básicos e intermedio y con un importante número de hablantes pasivos (2009). Este grupo se caracteriza no sólo por presentar los menores índices de bilingüismo, sino que, además, las habilidades lingüístico-comunicativas que logra alcanzar no le permiten una producción lingüística desarrollada (Durán et al., 2007; Zúñiga, 2007; Gundermann y otros, 2008).

Para el caso de Tirúa, zona que nos ocupa en este estudio, se ha observado un escenario poco favorable para la lengua, pues ésta ha ido reduciendo su campo de acción y se encuentra en la actualidad al alcance, principalmente, de los adultos y ancianos, quienes la usan fundamentalmente en sus interacciones cotidianas, en ceremonias religiosas ancestrales y en eventos públicos y formales intracomunitarios (reuniones, encuentros, ngillatun, etc.), mientras que entre los jóvenes se

2 Los escolares mapuche de Tirúa llaman a su lengua chedungun, mapudungun y lengua mapuche, por ello en este artículo utilizaremos indistintamente estas tres denominaciones. 
observa un uso muy precario, el que se torna casi inexistente entre los niños. En la interacción familiar, la lengua oficial parece ser el vehículo principal de comunicación y la enseñanza del mapudungun ido pasando progresivamente a manos de la escuela (Henríquez, 2014, 2015).

En este contexto, nos parece relevante realizar estudios descriptivos para determinar el estado actual del sistema lingüístico mapuche, especialmente en los grupos generacionales más jóvenes. Esto porque, como se sabe, la restricción funcional de una lengua producto del contacto lingüístico provoca cambios no solo en la competencia lingüística de sus usuarios, sino que también se manifiesta en el plano formal de la lengua (Dorian, 1980; Andersen, 1982; Appel y Muysken, 1996; Grinevald, 1997; Thomason y Kaufman, 1998; Crystal, 2001; Blas Arroyo, 2008).

Específicamente, este trabajo tiene como foco identificar y describir los rasgos prominentes ${ }^{3}$ que caracterizan la fonología segmental del chedungun que manejan los niños mapuche de dos localidades de la comuna de Tirúa: Ranquilhue y Primer Agua.

\section{Descripciones fonológicas del mapudungun}

Existen diversas descripciones fonológicas especializadas del mapuche hablado por adultos. De estas descripciones, destacamos los trabajos de: Suárez (1959); Echeverría (1964); Salas (1976); Lagos (1981); Álvarez-Santullano (1986a, 1986b); Sánchez (1989); Salamanca (1997); Salamanca y Quintrileo (2009) y Sadowsky et al., (2013).

La primera descripción fonológica especializada del mapuche hablado en Chile, preparada directamente con materiales vivos, fue realizada por Echeverría (1964). De su análisis, resulta un inventario de 26 fonemas, de los cuales 6 son vocales: / i, e, a, ü, o, u/ y 20 son consonantes: / p, t , t, $\mathrm{k}, \mathrm{tr}, \mathrm{t} \int, \mathrm{f}, \theta, \mathrm{s}, \mathrm{r}, \mathrm{y}, \mathrm{w}, \mathrm{m}, \mathrm{n}, \mathrm{n}, \mathrm{j}, \mathrm{l}, 1,1, \Lambda$ /. Según Salas, la descripción de Echeverría es "un trabajo académicamente sólido y realista, confirmado salvo en detalles menores de la realización alofónica y en la interpretación fonémica de algunos segmentos de estatus dudoso- por todos los estudios fonológicos posteriores" (1992b: 507).

3 Por rasgos prominentes se entiende aquí aquellas características fonético-fonológicas que no se reportan en otras variantes del mapudungun o la frecuencia/distribución atípica de un segmento reportado en otras variantes (Henríquez y Salamanca, 2012). 
En el año 1976, Salas publica su "Esbozo fonológico del mapudungun, lengua de los mapuches o araucanos de Chile central". Allí presenta un inventario de veintisiete fonemas segmentales, seis vocales y veintiuna consonantes. A diferencia de Echeverría, asigna estatus fonémico a la fricativa velar sonora $[\gamma]$, y considera que la fricativa sibilante alveolar áfona [s] y la fricativa sibilante alveopalatal áfona [S] son alófonos del mismo fonema.

En el año 1981, Lagos publica "El estrato fónico del mapudungun(n)", correspondiente a la lengua hablada en la IX Región. Este autor presenta un inventario de 26 fonemas segmentales, de los cuales 6 son vocales y 20 son consonantes. Las diferencias con las descripciones anteriores son menores; por ejemplo, no asigna estatus fonémico a [Y], como sí lo hace Salas (1976).

Estos trabajos descriptivos muestran una alta homogeneidad lingüística entre los hablantes de mapudungun de la zona central. En efecto, las vocales descritas coinciden plenamente, en tanto que el inventario de consonantes evidencia algunas diferencias menores en la interpretación de ciertos segmentos de estatus dudoso.

Con respecto al mapuche pewenche, relevamos los trabajos de Sánchez (1989) y Salamanca (1997), ambos realizados en la zona de Alto Bío-Bío. Según Sánchez, los pewenches del Alto Bío-Bío realizan las fricativas labiodental e interdental como sonoras (o ensordecidas) [v] y [ð], pero nunca como sordas. Además, sostiene que en esta variante no habría distinción entre los sonidos alveolares e interdentales (excepto /s/ versus /ð/)4. Este hecho diferenciaría al pewenche de Alto Bío-Bío del picunche del llano central y del pewenche meridional.

Salamanca (1997), a diferencia de Sánchez, asigna estatus fonémico

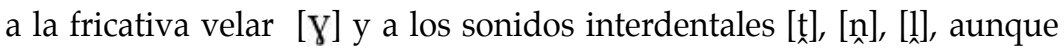
reconoce que en algunos hablantes la distinción entre estos últimos y los sonidos alveolares no es tan regular (1997, p. 120). Con respecto a los fonemas /ð/ y /v/, declara que el fonema fricativo interdental se realiza siempre sonoro, en lo que coincide con Sánchez; en cambio, el

4 En una descripción fonológica del chedungun hablado por escolares pewenches del Alto Bío-Bío, observamos escasas realizaciones de los fonos $[t, n, l]$ entre los niños de Cauñicu; sin embargo, los escolares de la comunidad de Butalelbun presentaban, de manera sistemática, la distinción entre alveolares e interdentales (Henríquez y Salamanca, 2012, 2015). 
fonema fricativo labiodental, además de la variante labiodental sonora [v], presentaría ocasionalmente la realización fricativa labiodental áfona [f]. En esto se distancia de Sánchez.

El dialecto huilliche fue descrito por Alvarez-Santullano (1986a, 1986b). A juicio de Salas: "los datos de Alvarez-Santullano muestran un alto grado de desmantelamiento del sistema fonológico tradicional, reflejo del estado terminal del huilliche osornino. En estas condiciones sólo se pueden hacer meras conjeturas sobre lo que fue la fonología del huilliche en las etapas anteriores al período desintegrativo" (Salas, 1992b, p. 509-510).

Con respecto al mapuche de Tirúa, zona relevante para los propósitos de este estudio, destacamos el trabajo de Salamanca y Quintrileo (2009), quienes publican una descripción fonológica del mapuche hablado en la Provincia de Arauco; específicamente, en la comuna de Tirúa. Los informantes que colaboraron en esta investigación fueron cuatro hablantes adultos bilingües residentes en la Comuna de Tirúa a quienes se les aplicó una lista léxica de 300 ítems. Según el análisis de estos autores, el mapuche hablado en Tirúa tiene 24 fonemas segmentales. De ellos, 6 son vocales: /i, e, a, ü, u, o/ y 18 son consonantes: / p, t, tr, č, k, v, ठ, w, g, s, y, r, m, n, j, n, l, א/

Para estos autores, en el mapuche hablado en Tirúa, a diferencia de lo que sucede en algunos otros dialectos, los sonidos interdentales $[t]$, [n], [1] no se presentan como fonemas distintos, sino como variantes de las realizaciones alveolares. Además, coinciden con Echeverría en que [ $]$

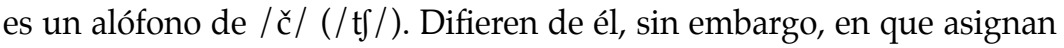
estatus fonémico a $[\gamma]$.

Por último, el estudio fonológico más reciente del mapudungun fue realizado por Sadowsky y otros (2013) con hablantes de Isla Wapi. Estos autores identifican 22 fonemas consonánticos y 6 vocálicos. Señalan la existencia de las interdentales y su estatus de fonemas, el estatus de fonema del fono [j] y la realización más frecuente de [ə] para la sexta vocal. 


\section{La investigación}

\subsection{Objetivos}

1) Determinar, de acuerdo con el método distribucional, los fonemas segmentales y las realizaciones alofónicas del mapudungun de los escolares mapuche de la comuna de Tirúa.

2) Comparar este sistema fonológico con el que se presenta en las descripciones fonemáticas existentes del mapudungun en general y de la variante de Tirúa en particular.

3) Determinar los rasgos prominentes de la fonología descrita.

\subsection{Método ${ }^{5}$}

\subsubsection{Zona de estudio}

Para la realización de este estudio, hemos seleccionado la comuna de Tirúa que se destaca por su alta concentración de población indígena. De un total aproximado de 10.000 habitantes, el $70 \%$ es de origen mapuche.

\subsubsection{Los participantes}

La muestra es selectiva e intencionada, debido a la ventaja y utilidad que presenta para nuestro diseño de estudio, que requiere no tanto una representatividad de elementos de una población, sino una cuidadosa y controlada elección de sujetos con ciertas características específicas (Hernández y Almeida, 2005).

De acuerdo con lo anterior, y para el logro de nuestros objetivos, trabajamos con un grupo de 20 escolares, que cumplían con el siguiente perfil:

(1) Ser miembro de alguna comunidad mapuche de la comuna de Tirúa (2) Autodefinirse como mapuche o que al menos uno de sus progenitores perteneciera a la etnia mapuche (3) Tener entre 12 y 15

5 La metodología llevada a cabo en este estudio es la misma que se presentó en el artículo "Rasgos prominentes de la fonología segmental del chedungun hablado por escolares del Alto Bío-Bío" (Henríquez y Salamanca, 2012, p. 153-171). 
años $^{6}(4)$ Pertenecer a un establecimiento educacional rural adscrito al Programa EIB (5) Estar cursando $7^{\circ}$ u $8^{\circ}$ año básico.

El número de niños que formó parte de la muestra, así como las localidades y escuelas seleccionadas, fue un proceso que se fue configurando a medida que desarrollamos el trabajo de campo, pues dependió de factores empíricos relacionados con la realidad lingüística de cada comunidad y/o escuela consultada.

En definitiva, para la configuración de la muestra nos guiamos por un principio rector: se buscó aquellas escuelas y comunidades que distintos agentes (profesores mapuche, docentes directivos, comuneros, longkos, dirigentes sociales, coordinadores municipales del PEIB, funcionarios de la Dirección de Administración de Educación Municipal (DAEM) y de la Corporación nacional de Desarrollo Indígena (CONADI), etc.) nos señalaron como zonas de mayor retención del vernáculo (donde "más se habla la lengua"). El trabajo de campo contempló varias visitas de acercamiento a las diferentes escuelas y comunidades y más tarde la etapa de recogida de datos a las localidades de Primer Agua y Ranquilhue.

Los 20 escolares que participaron en el estudio accedieron a responder la lista léxica y las preguntas de texto en mapudungun de manera totalmente voluntaria y con el consentimiento informado de sus padres.

\subsubsection{Estrategias para la recolección del material}

Para la elicitación del corpus fonético-fonológico se utilizaron las siguientes estrategias:

\subsubsection{Aplicación de una lista léxica ${ }^{7}$}

Se utilizó una lista léxica de 64 ítems, compuesta de palabras relativas al mundo inmediato y circundante del niño, tales como partes del cuerpo, alimentos, términos de parentesco, flora, fauna, colores, numerales, etc. $\mathrm{Al}$ seleccionar la lista de palabras tuvimos especial cuidado en incluir todos los fonemas de la lengua mapuche, especialmente aquellos que han sido objeto de discusión entre los especialistas, como los segmentos

6 Con respecto a la edad de los participantes, creemos que al término del segundo ciclo básico, cuando los escolares tienen entre 12 y 15 años, es esperable que hayan alcanzado un asentamiento definitivo de ambos sistemas fonológicos, gracias a la socialización temprana en ambas lenguas, con sus padres, pares y a la intervención de la escuela como agente del bilingüismo.

7 La lista léxica fue sometida a juicio de dos expertos y revisada por dos hablantes de mapudungun. 
inestables (Croese, 1980) y aquellos que no están presentes en el patrón

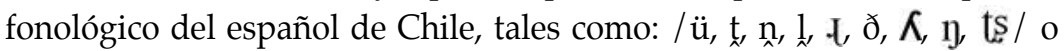
que están presentes, pero con una distribución fonotáctica distinta, como es el caso de $/ \mathrm{j} /$.

\subsubsection{Narración oral de una historia breve}

Esta narración tuvo por objeto complementar los datos fonéticofonológicos obtenidos a través de la lista léxica.

En términos generales, diseñamos y presentamos a los niños un relato breve en mapudungun, que contenía palabras seleccionas ${ }^{8}$ de la lista léxica. Luego de escuchar la grabación en dos oportunidades, debían narrar la historia en mapudungun o contar lo que recordaban de ella. En los casos en que los escolares tuvieron dificultad para narrar el cuento en mapudungun, o si en su relato no aparecían las palabras seleccionadas, se les realizaron algunas preguntas específicas sobre la historia para lograr la elicitación de éstas.

El texto de la historia fue revisado, corregido y grabado por dos colaboradores mapuche hablantes. Luego, se generó una versión grabada de esta historia, en la variante lafkenche, la cual estuvo a cargo de un hablante nativo de la zona.

\section{Resultados}

\subsection{Consideraciones previas}

A continuación, presentaremos los rasgos fonético-fonológicos más prominentes $^{9}$ de la fonología del mapuche de Primer Agua y Ranquilhue, que resultan al comparar estos sistemas fonológicos con aquellos que se presentan en las descripciones fonemáticas existentes del mapudungun en general y, más concretamente, con la variante mapuche de Tirúa en particular; es decir, el contraste se realizará principalmente con el sistema fonológico descrito por Salamanca y Quintrileo (2009) para hablantes mapuches adultos de la zona de Tirúa.

8 Estas palabras fueron seleccionadas de la lista léxica por los segmentos que contenían, específicamente fonemas del mapudungun ausentes en el inventario del español.

9 Entendemos por rasgos prominentes aquellas características fonético-fonológicas que no se reportan en otras variantes del mapudungun o la frecuencia/distribución atípica de un segmento reportado en otras variantes (Henríquez y Salamanca, 2012). 
En este análisis distinguimos entre variantes vernáculas o tradicionales, de aquellas emergentes (no vernáculas o no tradicionales). Las primeras son aquellas registradas en las descripciones fonemáticas del mapudungun y, más específicamente, que forman parte del sistema fonológico del mapudungun de los adultos de la zona. Las segundas, emergentes o no vernáculas, constituyen todas aquellas variantes alofónicas que emergen del habla de los escolares de ambas localidades y que no forman parte del habla de los adultos de la zona. Son aquellos usos innovativos (Escobar y Wölck, 2009) que se han relevado como rasgos prominentes por ser exclusivos de los sistemas fonológicos de estos niños.

\subsection{Rasgos prominentes}

\subsubsection{Vocales}

De acuerdo con el análisis del material recolectado en la zona de Tirúa, se ha podido establecer un inventario de 5 fonemas vocálicos segmentales del mapudungun de los escolares de ambas localidades: /i, e, a, o, u /. En este inventario, como se observa, es notable la ausencia del fonema / u / (ü) alto posterior no redondeado (sexta vocal).

Tanto en Primer Agua como en Ranquilhue, los fonemas /e/, /a/, /o/ presentan un solo alófono cada uno ([e], [a], [o]), en tanto que el fonema /i/, presenta dos: [i] alto anterior no redondeado y [u] alto posterior no redondeado.

El fonema $/ \mathrm{u} /$, por otra parte, presenta dos variantes alofónicas en Primer Agua: [u] alta posterior redondeada y [u] alta posterior no redondeada; y tres en Ranquilhue: [u] alta posterior redondeada, [u] alta posterior no redondeada y [ə] media central no redondeada.

Con respecto a la ocurrencia de estos dos fonos vernáculos [u] y [ə] es necesario especificar lo siguiente:

a) La aparición de los fonos [u] y [ə] es residual: en Primer Agua y Ranquilhue se observó un total de ocho realizaciones del fono [u] (cuatro en cada sector, de 45 y 46 posibles, respectivamente), mientras que el fono [ə] se registró en una sola oportunidad, en el sector de Ranquilhue. 
b) En Primer Agua, como indicábamos, las cuatro realizaciones del fono [u] ocurren de un total de 45 instancias efectivamente respondidas por los escolares en que era expectable la ocurrencia de alguna de las dos variantes vernáculas ([u] / [ə]]). Estas realizaciones se registran sólo en la palabra "tres" (/ kula/), la que se realiza como ['kula], en alternancia con las pronunciaciones mucho más frecuentes ['k illa] y ['kula]. Por ello, hemos interpretado el fono [u] como variante alofónica de los fonemas $/ \mathrm{i} / \mathrm{y} / \mathrm{u} /$. Tres estudiantes de esta zona realizan este fono vernáculo; los otros niños no producen ninguna palabra con esta vocal. En el resto de los ítemes respondidos fue sistemáticamente sustituida por $/ \mathrm{u} /$, como sucede en las palabras "día" (/antu/), "piojo" (/ turun/) y "pene" (/punumn/), las cuales se realizan siempre como ['antu], [tun] y [pu'nun], respectivamente.

c) En Ranquilhue se aprecia una situación bastante similar, ya que las 5 realizaciones vernáculas se dan dentro un total de 46 instancias efectivamente respondidas por los niños en que era expectable la ocurrencia de uno de los dos fonos vernáculos ([u] o [ə]). Estas escasas realizaciones se pueden observar en las palabras "tres" (/ kula/), "día (/anțu/), "boca" (/ wum/n /) y "fuego" (/ kutșal/), las cuales se realizan como ['kula], ['antə], [gun] y [ku'tșal], en alternancia con las pronunciaciones más fecuentes ['kila] ['antu], [gun], [kji'tsal] y [ku'tșal]. Esta escasísima frecuencia de [u] y su alternancia con [i] y [u] nos ha llevado a interpretarla como variante de /i/ y $/ \mathrm{u} /$; en tanto que la única realización de [ə], que ocurre en alternancia con $[\mathrm{u}]$, se ha interpretado como alófono de / u/. Estas realizaciones vernáculas son efectuadas por cuatro escolares de la zona. El resto de los colaboradores no realiza ninguna de estas variantes.

En resumen, la pérdida de estatus del fonema / u / en ambas zonas se sostiene en los siguientes argumentos:

a) Inconsistencia en las palabras elicitadas: las realizaciones del fonema son residuales en ambas zonas, esto quiere decir que en la mayoría de las palabras elicitadas, en que era expectable su ocurrencia, fue reemplazado sistemáticamente por $[\mathrm{u}]$ o por [i].

b) Inconsistencia en los informantes: tanto en Primer Agua como en Ranquilhue no se observa ningún niño que presente de manera consistente el fonema / $\mathrm{w} /$. La mayoría de los escolares lo sustituye por el fonema $/ \mathrm{u} / \mathrm{o} / \mathrm{i} /$. 
c) Frecuencia residual: al observar los porcentajes de realización de los fonos [u] y [ə] en las palabras efectivamente respondidas, se aprecia su bajísima frecuencia. Esta situación crítica se puede observar en la siguiente tabla, donde se presentan los porcentajes de realización de las variantes vernáculas y de los fonos de reemplazo [i] y [u] en aquellas palabras efectivamente respondidas en que era expectable la ocurrencia de [u] o [ə]:

Tabla 1.

Porcentaje de realizaciones de [u], [ə], [i] y [u]

\begin{tabular}{ccc}
\hline Primer Agua & Ranquilhue & \\
\hline$[\mathrm{u}] /[ə]$ & $8,89 \%$ & $10,87 \%$ \\
\hline$[\mathrm{i}]$ & $22,22 \%$ & $17,39 \%$ \\
\hline$[\mathrm{u}]$ & $68,89 \%$ & $71,74 \%$ \\
\hline
\end{tabular}

La ausencia del fonema / $\mathrm{u} /$ del inventario de vocales del mapudungun de estos escolares constituye un rasgo particularmente prominente, pues hace que este sistema difiera considerablemente de los sistemas vocálicos descritos para el mapuche en general (Echeverría, 1964; Salas, 1976; Lagos, 1981; Alvarez-Santullano, 1986a; Sánchez, 1989; Salamanca, 1997) y para el mapuche de Tirúa, en particular (Salamanca y Quintrileo, 2009).

\subsubsection{Consonantes}

\subsubsection{Serie labial}

En esta serie, el mapudungun que manejan los escolares de Primer Agua y Ranquilhue presenta 3 fonemas: /p, m, v/. Los dos primeros tienen sólo una realización alofónica cada uno: los fonos [p] y [m], respectivamente, mientras que el fonema / $/$ presenta tres realizaciones en Primer Agua: [v], [f] y [s], y dos en Ranquilhue [v] y [f].

Con respecto al fonema / v / es necesario destacar lo siguiente:

a) Hemos escogido el alófono [v] como la forma básica del fonema, porque es la realización más frecuente en las dos comunidades en estudio.

b) Constatamos la presencia del fono fricativo labiodental sordo [f] en ambas zonas, en lo que coincidimos con lo observado por Salamanca y 
Quintrileo (2009), quienes reportan la existencia de esta variante en el habla adulta en la zona de Tirúa, aunque señalan el claro predominio de la variante sonora. Entre las palabras que tienen realizaciones áfonas en nuestros datos se cuentan: "pan" (/kovke/) y "oveja”, (/ ovifa/), las cuales se realizan, ocasionalmente en ambos sectores, como ['kofkie] y [o'fija]. Además, en Ranquilhue, encontramos la palabra "cochayuyo" (/ koאov/), la cual se realizó únicamente como [ko'jof].

c) En la zona de Primer Agua también se observó una realización fricativa alveolar sorda [s]. Ocurrió en la palabra "pan" (/kovke/), la cual un estudiante realiza siempre como ['koskje].

\subsubsection{Serie dental y alveolar}

En la serie alveolar, el mapudungun de estos escolares presenta, en ambas zonas, cuatro fonemas: /t, n, s, 1/. En la serie dental, en cambio, se constata la existencia de sólo un fonema en Primer Agua (/ð/) y la ausencia de estos fonemas en Ranquilhue. Esto, desde un punto de vista fonémico. Desde un punto de vista fonético, en cambio, conviene precisar y distinguir lo que sucede en ambas zonas:

a) En Primer Agua, los fonemas alveolares /t/, /n/, /1/ presentan un solo alófono cada uno ([t], [n], [1]), en tanto que el fonema alveolar /s /, presenta tres variantes: la fricativa alveolar sorda [s], la fricativa alveopalatal sorda [ $]$ ] y la fricativa interdental sorda [ $\theta]$. Estas tres realizaciones se encuentran en variación libre. Así, por ejemplo, la

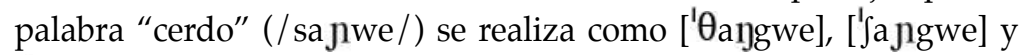
['sangwe], aunque los niños manifiestan preferencia por la última realización. Dado que los fonos [ [] y $[\theta]$ no se reportan en el habla adulta de la zona como alófonos de /s / (Salamanca y Quintrileo, 2009), su surgimiento se releva como un rasgo prominente ${ }^{10}$. Además, destacamos el hecho de que $[\theta]$ no había sido reportada en ninguna de las descripciones tradicionales como alófono de /s/.

b) Con respecto a la serie dental y según nuestro corpus, el fonema [ð] presenta una sola realización alofónica /ð/. A diferencia de lo

10 En la descripción de la variante del mapuche central (Araucanía), tanto Salas $(1976,1978)$ como Lagos (1981), registran el fono [J] como alófono de /s /. 
señalado por Salamanca y Quintrileo (2009), en Primer Agua no hemos registrado la variante interdental áfona $[\theta]$ del fonema /ð/.

c) En relación con los fonemas (inter)dentales $/ \mathrm{t} / \mathrm{h} / \mathrm{n} / \mathrm{y} / \mathrm{l} / \mathrm{l}$, podemos señalar que éstos no forman parte del inventario fonológico de Primer Agua, pues en todas aquellas palabras realizadas, en que era expectable su ocurrencia, fueron reemplazados en un $100 \%$ por los fonos alveolares [t], [n] y [1]. Es decir, no se registró ninguna realización interdental de estos fonemas. Así, palabras como "día, sol" (/antu/), "pie, pata" (/ namum y "quila" (/ kula/) se realizaron siempre como ['antu], [na'mun] y ['kiila], nunca con interdentales.

En Ranquilhue, los fonemas alveolares /t, n, s, l/ presentan las siguientes realizaciones alofónicas:

a) El fonema alveolar / s / , a diferencia de los que sucede en Primer Agua, sólo presenta una realización alofónica ([s]). En este caso, nuestros datos coinciden con lo descrito por Salamanca y Quintrileo (2009), quienes reportan sólo esta variante. Del mismo modo, encontramos este segmento sólo en posición inicial y con una baja frecuencia de aparición.

b) Los fonemas alveolares /n/ y / / presentan dos alófonos cada uno: [n], [n] y [1], [1], respectivamente; en tanto que el fonema / $\mathrm{t} /$ tiene un solo alófono [t]. Esto porque en este sector hemos constatado la existencia de algunas realizaciones residuales de los fonos interdentales [n] y [ 1], las cuales ocurren siempre en alternancia con los fonos alveolares [n] y [1], y son superadas largamente en cantidad por éstos, en todas aquellas palabras donde era expectable la ocurrencia de los interdentales. Es por ello que los fonos [n] y [1] los hemos interpretado como alófonos de los fonemas alveolares /n/ $\mathrm{y} / 1 /$, respectivamente. El fono interdental [ $\mathrm{t}$ ], al igual que en Primer Agua, no registra ocurrencias, puesto que fue reemplazado en un $100 \%$ por el fono alveolar $[\mathrm{t}]$.

En relación con los fonemas interdentales / $t$, n $\mathrm{n}$ $1 /$ /, coincidimos con Salamanca y Quintrileo (2009), quienes no los incluyen en su lista de consonantes.

c) Con respecto al fonema interdental (/ð/), en Ranquilhue no nos fue posible determinar el estatus de este fonema, ya que todas las palabras 
consultadas para su elicitación no eran de dominio de los escolares, pese a ser palabras del mundo inmediato y de uso cotidiano entre los hablantes ("mujer", "sal", "montaña", "amarillo", etc.); incluso, al preguntar por ítemes alternativos, no obtuvimos respuesta de parte de éstos, por lo tanto no podemos postular la ausencia o pérdida del fonema en esta zona, debido a la falta de datos que respalden una u otra hipótesis. (Esta situación la hemos destacado marcando el fonema en un paréntesis $(/ ð /)$ en los cuadros presentados en la sección 4.3).

Para finalizar el análisis de la serie dental y alveolar, presentamos a continuación una tabulación del rendimiento de los fonos (inter)dentales, [t, n y l] en ambas zonas. La situación crítica de éstos se puede observar en la siguiente tabla, en que se presentan los porcentajes de realización de las interdentales, en aquellas palabras efectivamente respondidas por los niños en que era expectable su realización.

Tabla 2.

Porcentaje de realización de los fonos interdentales

\begin{tabular}{ccc}
\hline & Primer Agua & Ranquilhue \\
\hline$[\mathrm{t}]$ & $0 \%$ & $0 \%$ \\
\hline$[\mathrm{n}]$ & $0 \%$ & $8,82 \%$ \\
\hline$[1]$ & $0 \%$ & $18,75 \%$ \\
\hline
\end{tabular}

\subsubsection{Alveopalatal}

En esta serie, el mapudungun de los escolares presenta un fonema: $/ \mathrm{f} /$, el cual tiene, en ambos sectores, una realización alofónica: el fono alveopalatal fricativo sordo []]. Es interesante observar la ausencia total del fono africado alveopalatal sordo $[\mathrm{t}]$ ]. Así, por ejemplo, los escolares realizan las palabras "pescado" y "pierna" como ['Jalwa] y[jan], nunca como ['tfalwa] o [tfan]. En esto nos distanciamos de Salamanca y Quintrileo (2009), quienes registran ambos fonos en la zona y asignan estatus fonémico a $[\mathrm{t} f]$ por ser el más frecuente entre los adultos.

En nuestra descripción, la presencia exclusiva del fono alveopalatal fricativo sordo en ambas zonas de estudio es un rasgo relevante en el sistema de estos niños. 
Por otra parte, desde un punto de vista dialectal, es interesante constatar el funcionamiento del fono [J]. Así, Suárez (1959) asigna estatus fonémico a $/ \mathrm{f} /$, pero también a $/ \mathrm{t} \int /$, mientras que en otras variantes del mapudungun este fono se ha reportado como un alófono de / s / (Salas, 1976; Lagos, 1981) ${ }^{11}$. En la descripción fonológica del mapudungun de Isla wapi, Sadowsky y otros (2013), otorgan estatus fonémico a $/ \int /$.

\subsubsection{Retrofleja}

En esta serie, el mapudungun hablado por los escolares presenta dos fonemas: en Primer Agua, / ts, $\mathrm{t}_{\mathrm{f}}$ /; y en Ranquilhue, / ts, $\mathbf{z}_{\mathrm{l}} /$.

Con respecto al fonema africado retroflejo / ts / es necesario destacar las siguientes particularidades:

a) Tanto en Primer Agua como en Ranquilhue hemos constatado la ocurrencia de dos realizaciones de este fonema: un alófono vernáculo africado alveolar sordo [ts] y una variante emergente $[\mathrm{t}+\mathrm{r}]$.

b) En ambas zonas destacamos la alta frecuencia de la secuencia $[t+r]$, que ocurre en alternancia con el fono [ts], situación que nos lleva a la interpretación de ambos como realizaciones del mismo fonema. En muchas ocasiones, esta realización emergente aparece reemplazando al fono vernáculo. Por ejemplo, algunos niños realizan las palabras "perro" y "ají" como ['tsewa] y ['tsapi] en alternancia con ['trewa] y ['trapi], pero también hay escolares que las realizan exclusivamente como ['trewa] y ['trapi]. La emergencia de la realización [ $t+\mathbf{r}$ ] se releva como un rasgo prominente, pues no había sido reportada en ninguna de las descripciones del mapuche. Se trataría de una realización castellanizada del fono originario [ts], explicable por transferencia fonológica del castellano.

c) En Ranquilhue, el fono [ts] es la variante preferida por los niños, alcanzando un 53,57\% en las palabras efectivamente respondidas. En primer Agua, en cambio, su frecuencia es menor, pues sólo representa el $16 \%$ de las ocurrencias. Pese a esto, hemos seleccionado este fono vernáculo como el representante del fonema en ambas localidades,

11 Es probable que estas diferencias se vinculen más bien con la interpretación fonético-fonológica que con distinciones estrictamente dialectales. 
reconociendo, eso sí, el estado crítico que presenta, producto de altos índices de alternancia y reemplazo. Como esta situación es más evidente en Primer Agua, hemos optado por destacar el fonema en color gris $/ \mathrm{ts} /{ }^{13}$, lo que refleja su situación de inestabilidad en esta zona.

Con respecto al fonema retroflejo, aproximante / $/ \mathrm{T}$ o fricativo $/ \mathrm{Z}_{\mathrm{b}} /$, es necesario destacar lo siguiente:

a) En Primer Agua, el fonema / $\mathrm{f} /$ tiene dos realizaciones vernáculas: un alófono aproximante retroflejo [.] y uno fricativo retroflejo [z, ]. De éstos, el más frecuente es el aproximante, por ello lo hemos relevado como el representante del fonema. En Ranquilhue, también hemos registrado estos dos fonos, pero dado que el más frecuente es el fricativo, lo hemos escogido como el representante del fonema; de ahí, entonces, que / $\mathrm{t} /$ sea la forma básica del fonema en Primer Agua, y / $\mathrm{z}_{\mathrm{b}} /$ lo sea de Ranquilhue.

b) Destacamos la presencia, en ambas localidades, de tres variantes no vernáculas de este fonema retroflejo: [r] vibrante simple alveolar sonora; [r] vibrante múltiple alveolar sonora y [dz] africada retrofleja sonora. Estas ocurren en alternancia con los fonos vernáculos [-] y [z], por lo que las hemos interpretado como alófonos de / $\mathrm{f} / \mathrm{y} / \mathrm{z}$. l, aunque en algunas ocasiones aparecen en reemplazo de éstos. Ejemplo: los escolares de ambos sectores realizan la palabra "diez" como ['mari], en alternancia con ['mazi i] y ['ma,ii], y la palabra "siete", como ['dzeyle] y ['reyle], en alternancia con ['z,eyle] y ['.'eyle]; en cambio, la palabra "aji" la realizan como [mer'kien] y nunca como [mez,kien] o [me,t'kien].

La emergencia de las variantes [r], [r] y [dz] se destaca como un rasgo prominente de estos sistemas fonológicos. Salamanca y Quintrileo (2009) sólo reportan dos alófonos para el fonema / $z_{\iota} /:$ un fono fricativo

12 En un estudio con hablantes bilingües de la Araucanía de entre 18 y 30 años, se registró esta realización castellanizada en el grupo con menor competencia en la lengua originaria (Henríquez, 2004).

13 No otorgarle el estatus de fonema en Primer Agua, por su baja frecuencia, podría sugerir que en Ranquilhue este segmento estaría fonológicamente más vital y esto no refleja la realidad observada. En efecto, si bien el fonema está presente en ambas localidades, su situación es crítica en toda la zona, pues está siendo reemplazado sistemáticamente por la realización $[t+r]$, pese a que en Ranquilhue [tș] aparece en un mayor número de ocasiones, según las palabras respondidas; sin embargo, si el análisis se realiza según las palabras expectables, esta situación es menos favorable, pues sólo alcanza un $14 \%$ de las ocurrencias. 
retroflejo sonoro y un fono fricativo retroflejo sordo. La hipótesis sobre la ocurrencia de estas variantes es la misma que esbozamos más arriba: estamos en presencia de usos innovativos producto de un proceso de castellanización de la matriz fonológica del mapudungun que manejan estos niños.

\subsubsection{Serie palatal y velar}

En esta serie, se observa la ocurrencia, en ambas localidades, de dos fonemas: $\mathrm{n}, \mathrm{j} /$. Destacamos la ausencia del fonema palatal $/ \boldsymbol{\Lambda} /$, el cual ha sido reemplazado sistemáticamente por el fonema aproximante palatal $/ \mathrm{j} /$. En efecto, en todas aquellas palabras respondidas por los niños en que era expectable la ocurrencia del fonema palatal lateral $/ \Lambda /$, fue reemplazado por $/ \mathrm{j} /$.

La ausencia del fonema palatal $/ \Lambda /$ del mapudungun de estos hablantes constituye un rasgo particularmente prominente, pues este fonema siempre ha formado parte de las descripciones del mapuche (Echeverría, 1964; Salas, 1976, 1978; Lagos, 1981; Alvarez-Santullano, 1986a; Sánchez, 1989; Salamanca, 1997; Salamanca y Quintrileo, 2009).

Por otra parte, desde una perspectiva fonética, nuestros datos muestran que $/ \mathrm{j} / \mathrm{y} / \mathrm{j} /$ tienen las realizaciones vernáculas $[\mathrm{j}]$ y $[\mathrm{j}]$, respectivamente. Ahora, el fonema palatal / $\mathrm{n} /$ presenta, además, otras tres variantes: $[\mathrm{n}],[\mathrm{\eta}]$ y $[\mathrm{m}]$. Con respecto al funcionamiento de éstas, es necesario especificar lo siguiente:

a) Las variantes nasal alveolar sonora [n] y nasal velar sonora [n] ocurren tanto en Primer Agua como en Ranquilhue, mientras que la variante nasal bilabial sonora $[\mathrm{m}]$ se registró sólo en este último sector.

b) Estos tres fonos ocurren sólo en el postmargen silábico, en alternancia con $[\mathrm{n}] \mathrm{y}$, en algunas ocasiones, en reemplazo de [n]; Por ejemplo, cuando a los niños se les consulta por la palabra "cerdo" (/ sa jwe/), responden ['sajwwe] o ['sangwe], siendo esta última realización la más común. Sin embargo, cuando son consultados por la palabra "ají molido" (/me.jkej/), los niños de Primer Agua responden siempre como [mer'kien] y los de Ranquilhue, [mer'kien] o [mer'kiem], nunca [me.j'kjej].

c) Destacamos la alta frecuencia de estas tres variantes no tradicionales, las cuales superan a la variante vernácula $[\mathrm{n}]$ en el postmargen, por 
lo que se releva como otro de los rasgos prominentes que caracterizan la fonología de estos niños. Su carácter innovativo se evidencia al contrastar estos sistemas con otras variedades del mapudungun y con el habla adulta de la zona.

En la serie velar, en tanto, el mapudungun hablado por los escolares presenta los siguientes fonemas: $/ \mathrm{k}, \mathrm{y}, \mathrm{\gamma}, \mathrm{w} /{ }^{14}$. Los fonemas $/ \mathrm{k}, \mathrm{y} /$ tienen alófonos adelantados ante vocales anteriores. Así se aprecia en las palabras "madre" (/ juke/) y "ojos" (/ je/), las cuales se realizan como ['jukje] y [nje], respectivamente.

El fonema $/ \mathrm{g} /$, además de sus dos variantes tradicionales (nasal velar sonora $[\mathrm{n}]$ y nasal postpalatal sonora $[\mathrm{n}] \mathrm{j}]$ ), presenta una serie de otras realizaciones alofónicas:

- $\quad$ Primer Agua : [i], [v], [b], [gi], [Yj] y [n]

- $\quad$ Ranquilhue: [i], [u], [b], [gj], [Yj], [j] y [n]

Con respecto a estas variantes se puede consignar lo siguiente:

a) Ocurren en alternancia con el alófono vernáculo [ $\mathrm{n}^{\mathrm{i}}$ ], aunque en la mayoría de las ocasiones aparecen en reemplazo de éste. Así, por ejemplo, la palabra "rogativa mapuche" (/ jiKatun/) los estudiantes

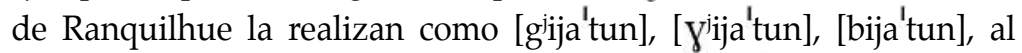
igual que los de Primer Agua, quienes agregan [vija'tun]. En ninguno de los dos sectores ocurre [njiKa'tun]. Del mismo modo, la palabra "hermana" (/lampen/) se realiza como [la'mien] y [la'muen] ${ }^{15}$, aunque también con la variante vernácula [lam'njen]. Otro caso de reemplazo y alternancia se observa en la palabra "ojo" (/ pe/), que se realiza como [nje], en alternancia con [je], aunque la mayoría de los estudiantes opta por realizarlo como [je]. Producto de estas alternancias y sustituciones, hemos interpretado estas variantes no tradicionales como alófonos del fonema velar $/ \mathrm{y} /$.

14 Hemos interpretado el fono [ү] como un fonema y no como un mero desarrollo consonántico de la sexta vocal.

$15 \mathrm{Al}$ consultar a tres mapuche-hablantes de alta competencia, originarios de la zona, nos señalaron que el reemplazo o alternancia de $[\mathrm{r}]$ por [u] o [i] es característico de la zona y de uso relativamente frecuente entre los jóvenes y adultos; concretamente, esta alternancia se da en la palabra "hermana", la cual algunos hablantes realizan no sólo como [lam'njen], sino también como [la'muen] o [la'mien], aunque nos señalaron que el primer enunciado era el más "apropiado" y más frecuente entre los hablantes ancianos. 
b) Cada una de estas variantes presenta una baja frecuencia; pero, en conjunto, superan ampliamente las realizaciones vernáculas. Así, el fonema velar $/ \mathrm{y} /$ en ambas zonas se encuentra en un estado de alta inestabilidad, debido a las situaciones de alternancia y reemplazo que lo afectan. La emergencia de estas variantes no reportadas en las descripciones de referencia las destacamos como otro rasgo prominente.

Para graficar la situación del fonema velar en la zona y la relevancia de las variantes emergentes, en la siguiente tabla se muestra los porcentajes de realización que alcanzan las variantes del fonema / $\mathrm{y} /$, en aquellas palabras efectivamente respondidas por los niños en las que era expectable la ocurrencia de $\left[\eta^{j}\right]$ o [n].

Tabla 3.

Porcentaje de realización de las variantes del fonema / y/

\begin{tabular}{ccc}
\hline Variantes de $/ \mathrm{y} /$ & \% Primer Agua & \% Ranquilhue \\
\hline$[\mathrm{p}] /[\mathrm{y}]$ & 15,38 & 8,57 \\
\hline$[\mathrm{n}]$ & --- & 8,57 \\
\hline$[\mathrm{n}]$ & 11,54 & 25,71 \\
\hline$\left[\mathrm{\gamma}^{\mathrm{j}}\right]$ & 23,08 & 14,29 \\
\hline$\left[\mathrm{g}^{\mathrm{j}}\right]$ & 11,54 & 25,71 \\
\hline$[\mathrm{b}]$ & 3,85 & 2,86 \\
\hline$[\mathrm{v}]$ & 3,85 & --- \\
\hline$[\mathrm{i}]$ & 26,92 & 2,86 \\
\hline$[\mathrm{u}]$ & --- & 11,43
\end{tabular}

Finalmente, con respecto al fonema $/ \mathrm{\gamma} /$, registramos dos realizaciones

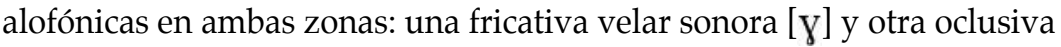
velar sonora $[\mathrm{g}]$. Ambas alternan en palabras como "siete", la cual los estudiantes realizan como ['žejle] y ['z_egle]. El fonema /w/ también presenta dos realizaciones: un fono aproximante velar labializado sonoro $[w]$ y otro oclusivo velar sonoro [g]. Ambos ocurren en variación libre. Por ejemplo, la palabra "boca" (/wunn/) se realiza como [wun], en alternancia con [gun]. Este fono oclusivo [g] es, en ambas zonas, una variante emergente o uso innovativo de los fonemas $/ \mathrm{\gamma} / \mathrm{y} / \mathrm{w} /$. 


\subsection{Inventarios de fonemas}

A continuación se presentan los inventarios de fonemas del mapudungun de los niños de Primer Agua y Ranquilhue.

\subsubsection{Fonemas vocálicos}

Tabla 4.

Fonemas vocálicos de Primer Agua y Ranquilhue

\begin{tabular}{llll}
\hline & Anteriores & Centrales & Posteriores \\
\hline Altas & /i $/$ & & $/ \mathrm{u} /$ \\
\hline Medias & $/ \mathrm{e} /$ & $/ \mathrm{o} /$ \\
\hline Bajas & & \\
\hline
\end{tabular}

\subsubsection{Fonemas consonánticos ${ }^{16}$}

Tabla 5.

Fonemas consonánticos presentes en Primer Agua

\begin{tabular}{|c|c|c|c|c|c|c|c|c|c|}
\hline & & Bilab. & $\begin{array}{l}\text { Labio- } \\
\text { dental }\end{array}$ & $\begin{array}{l}\text { Inter- } \\
\text { dental }\end{array}$ & Alveolar & $\begin{array}{l}\text { Alveo- } \\
\text { palatal }\end{array}$ & $\begin{array}{l}\text { Retro- } \\
\text { fleja }\end{array}$ & Palatal & Velar \\
\hline Oclusiva & & $/ \mathrm{p} /$ & & & $/ \mathrm{t} /$ & & & & $/ \mathrm{k} /$ \\
\hline Africada & & & & & & & $/ \mathrm{ts} /$ & & \\
\hline Nasal & & $/ \mathrm{m} /$ & & & $/ \mathrm{n} /$ & & & $/ \mathrm{n} /$ & $/ \mathrm{y} /$ \\
\hline Fricativa & & & $/ \mathrm{v} /$ & /ð/ & $/ \mathrm{s} /$ & $/ \mathrm{s} /$ & & & $/ \mathrm{y} /$ \\
\hline \multirow[t]{2}{*}{ Aprox. } & Obl. & & & & & & $/ x /$ & $/ \mathrm{j} /$ & \\
\hline & Lab. & & & & & & & & $/ \mathrm{w} /$ \\
\hline Lateral & & & & & $/ 1 /$ & & & & \\
\hline
\end{tabular}

Tabla 6.

Fonemas consonánticos presentes en Ranquilhue

\begin{tabular}{|c|c|c|c|c|c|c|c|c|c|}
\hline & & Bilab. & $\begin{array}{l}\text { Labio- } \\
\text { dental }\end{array}$ & $\begin{array}{l}\text { Inter- } \\
\text { dental }\end{array}$ & Alveolar & $\begin{array}{l}\text { Alveo- } \\
\text { palatal }\end{array}$ & $\begin{array}{l}\text { Retro- } \\
\text { fleja }\end{array}$ & Palatal & Velar \\
\hline Oclusiva & & $/ \mathrm{p} /$ & & & $/ \mathrm{t} /$ & & & & $/ \mathrm{k} /$ \\
\hline Africada & & & & & & & / ts $/$ & & \\
\hline Nasal & & $/ \mathrm{m} /$ & & & $/ \mathrm{n} /$ & & & $/ \mathrm{n} /$ & $/ \mathrm{y} /$ \\
\hline Fricativa & & & /v / & /ð/ & $/ \mathrm{s} /$ & 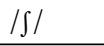 & & & $/ \mathrm{y} /$ \\
\hline \multirow[t]{2}{*}{ Aprox. } & Obl. & & & & & & $\left|z_{1}\right|$ & $/ \mathrm{j} /$ & \\
\hline & Lab. & & & & & & & & $/ \mathrm{w} /$ \\
\hline Lateral & & & & & $/ 1 /$ & & & & \\
\hline
\end{tabular}

16 Los fonemas de primer Agua y Ranquilhue destacados en color gris son aquellos cuya vitalidad está en estado crítico por baja frecuencia y altos índices de reemplazo. 


\section{Conclusiones}

A través del análisis de nuestro corpus, hemos constatado la existencia de una serie de rasgos fónético-fonológicos que caracterizan el mapudungun de los escolares de Tirúa y que constituyen, en general, variantes emergentes o innovaciones que distancian el sistema fonológico de estos niños del mapudungun en general y del mapuche de Tirúa, en particular.

Observamos que varios fonemas del mapudungun, principalmente aquellos ausentes de la matriz fonológica del español, presentan abundantes procesos de alternancia ${ }^{17} \mathrm{y}$ reemplazo, lo que ha provocado un evidente proceso de desfonologización o pérdida fonológica en los sistemas de ambos sectores (Andersen, 1982; Grinevald, 1997; Blas Arroyo, 2008).

Lo anterior tiene relación directa con los bajos niveles de competencia productiva en mapudungun que presentan estos niños, pues la lengua dominante en esta zona es el español, mientras que el mapudungun se usa sólo en algunos ámbitos sociales intracomunitarios, especialmente entre los adultos y ancianos de la comunidad (Henríquez, 2015). Con esto, queremos decir que estos fenómenos de alternancia y reemplazo se explicarían, en última instancia, porque estamos en presencia de hablantes inmersos en un escenario de contacto intenso y prolongado, en que el mapudungun está siendo desplazado por el español.

17 Las alternancias que se observan en el sistema de los niños no corresponden al fenómeno de fluctuación de fonemas, característico del mapudungun (Key, 1976; Salas, 1992a). 


\section{Referencias Bibliográficas}

Alvarez-Santullano, P. (1986a). Descripción Fonológica del Huilliche, un dialecto del mapuche o araucano del centro-sur de Chile. Tesis de Magister, Universidad de Concepción.

- (1986b). Descripción fonemática del Huilliche: estudio comparativo. Alpha, 2, 45-50.

Andersen, R. (1982). Determining the linguistic attributes of language attrition. En Lamber and Freed (Eds.), The loss of language skills. Rowley, Mass: Newsbury House Publishers.

Appel, R. y Muysken, P. (1996). Bilingüismo y contacto de lenguas. Barcelona: Ariel.

Blas Arroyo, J.L. (2008). Sociolingüística del español. Desarrollos y perspectivas en el estudio de la lengua española en contexto social. Madrid: Ediciones Cátedra.

Croese, R. (1980). Estudio dialectológico del mapuche. Estudios Filológicos, 15, 7-38.

Crystal, D. (2001). La muerte de las lenguas. Cambridge: Cambridge University Press.

Dorian, N. (1980). Language Shift in Community and Individual: The Phenomenon of the Laggard Semi-Speaker. International Journal of the Sociology of Language, 25, 85-94.

Duran, T., Catriquir, D. y Hernández, A. (2007). Revitalización del mapunzungun. Una visión crítica desde la educación intercultural, la sociolingüística y la antropología. Temuco: Universidad Católica de Temuco. Patrimonio cultural mapunche. Derechos lingüísticos y patrimonio cultural mapunche, Vol. I, 107-125.

Echeverría, M. (1964). Descripción fonológica del mapuche actual. Boletín del Instituto de Filología de la Universidad de Chile, XVI, 13-59. 
Escobar, A.M. y Wölck, W. (2009). Contacto lingüístico y la emergencia de variantes y variedades lingüisticas. Vervuert: Iberoamericana.

Grinevald, C. (1997). Language contact and language degeneration. En F. Coulmas (Eds.), The Handbook of Sociolinguistics (pp. 257-270). Oxford: Basil Blackwell.

Gundermann, H., Canihuan, J., Clavería, A., y Faúndez, C. (2008). Perfil sociolingüístico de comunidades mapuches de la Región del Biobio, Araucanía, los Ríos y los Lagos. Informe de Investigación. Santiago: CONADI - UTEM.

. (2009). Permanencia y desplazamiento, hipótesis acerca de la vitalidad del mapuzugun. RLA, 47(1), 37-60.

Hernández, J.M. y Almeida, M. (2005). Metodología de la investigación Sociolingüística. Málaga: Comares.

Henriquez, M. (2004). Interferencias del sistema fonológico español en el sistema fonológico mapuche de jóvenes hablantes bilingües. RLA, 42(2), 93-106.

. (2013). Vitalidad fonológica del mapudungun en escolares mapuches pewenches y lafkenches de la VIII región del Bío-Bío. Tesis de Doctorado en Lingüística. Universidad de Concepción.

. (2014). Estado del mapudungun en comunidades pewenches y lafkenches de la región del Bío-Bío: El caso de los escolares". RLA, 52(2), 13-40.

- (2015). Ámbitos de uso del mapudungun en comunidades pewenches y lafkenches de la región del Bío-Bío. Literatura y Lingüística, 31, 185-204.

Henríquez, M. y Salamanca, G. (2012). Rasgos prominentes de la fonología segmental del chedungun hablado por escolares pewenches del Alto Bío-Bío. Alpha, 34, 152-172.

. (2015). Vitalidad de la fonología segmental del chedungun hablado por escolares del Alto BioBío. Alpha, 41, 207-231. 
Key, M.R. (1976). La fluctuación de fonemas en la teoría fonológica. Signos: Estudios de Lengua y Literatura, 9, 137-147.

Lagos, C. (2012). El mapudungun en Santiago de Chile: vitalidad y representaciones sociales en los mapuches urbanos. RLA, 50(1), 161-184.

Lagos, D. (1981). El estrato fónico del mapudungu(n). Nueva Revista del Pacífico, 19-20, 42-66.

Sadowsky, S., Painequeo, H., Salamanca, G. y Avelino, H. 2013: "Mapudungun". Journal of the International Phonetic Association, 43, 87-96.

Salamanca, G. (1997). Fonemas segmentales del pewenche hablado en el Alto Bío-Bío. RLA, 35, 113-124.

Salamanca, G. y Quintrileo, E. (2009). Fonemas segmentales y muestra lexical del mapudungu hablado en Tirúa. $R L A, 47$, 13-35.

Salas, A. (1976). Esbozo fonológico del mapudungu, lengua de los mapuches o araucanos de Chile central. Estudios Filológicos, 11, 143-153.

. (1992a). El mapuche o araucano de Chile. Fonología, gramática y antología de cuentos. Madrid: Fundación MAPFRE América.

. (1992b). Lingüística mapuche. Guía bibliográfica. Revista Andina, 10(2), 473-537.

Sánchez, G. (1989). Relatos orales en pewenche chileno. Anales de la Universidad de Chile, 17, 289-360.

Suárez, J. (1959). The Phonemes of an Araucanian Dialect. International Journal of American Linguistics, XXV, 177-181.

Thomason, S. and Terrence, K. (1988). Language contact, creolization, and genetic linguistics. Bekerley/Los Angeles: University of California Press.

Zúñiga, F. (2007). Maudunguwelaymi am? ¿Acaso ya no hablas mapudungun? Acerca del estado actual de la lengua mapuche. Centro de Estudios Públicos, 105, 9-24. 